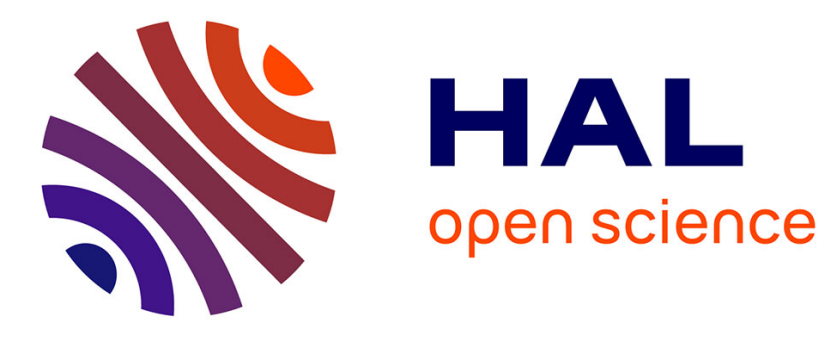

\title{
Hybrid force control with on/off electropneumatic standard distributors
}

\author{
Arnaud Sellier, Xavier Brun, Sylvie Sesmat, Jean-Marie Rétif, Xuefang \\ Lin-Shi, Daniel Thomasset, Mohamed Smaoui
}

\section{To cite this version:}

Arnaud Sellier, Xavier Brun, Sylvie Sesmat, Jean-Marie Rétif, Xuefang Lin-Shi, et al.. Hybrid force control with on/off electropneumatic standard distributors. International Journal of Fluid Power, 2006, 7 (1), pp.51-60. 10.1080/14399776.2006.10781239 . hal-00143562

\section{HAL Id: hal-00143562 https://hal.science/hal-00143562}

Submitted on 3 Apr 2019

HAL is a multi-disciplinary open access archive for the deposit and dissemination of scientific research documents, whether they are published or not. The documents may come from teaching and research institutions in France or abroad, or from public or private research centers.
L'archive ouverte pluridisciplinaire HAL, est destinée au dépôt et à la diffusion de documents scientifiques de niveau recherche, publiés ou non, émanant des établissements d'enseignement et de recherche français ou étrangers, des laboratoires publics ou privés. 


\title{
Hybrid force control with on/off electropneumatic standard distributors.
}

\author{
Arnaud Sellier*, Xavier Brun*, Sylvie Sesmat", Jean-Marie Retif**, Xuefang Lin-Shi**, Daniel \\ Thomasset", Mohamed Smaoui* \\ *Laboratoire d'Automatique Industrielle, INSA Lyon, Bâtiment Saint Exupéry, 25 Avenue Jean Capelle, 69621 \\ Villeurbanne Cedex, France, http://www-lai.insa-lyon.fr \\ Email contact: xavier.brun@insa-lyon.fr \\ *** Centre Génie Electrique de Lyon, INSA Lyon, Bâtiment Léonard de Vinci, 21 Avenue Jean Capelle, 69621 \\ Villeurbanne Cedex, France, http://cegely.cnrs.fr/
}

\begin{abstract}
This paper presents a new control method applied to the electro-pneumatic field. This strategy originates from the hybrid control theory recently developed for the control of asynchronous or synchronous electrical motors, e.g. Retif (2004). The interest of this strategy concerns the possibility of using standard on/off distributors instead of the usual servodistributors (components issued from proportional technology) for the force control of a pneumatic cylinder. Distributor components have less performance but are cheaper than a servodistributor. The aim is to obtain, with a distributor, the same performances as servodistributors on the global system.

Based on both cylinder and distributor models, the hybrid control presented here chooses the best state for each on/off distributor to reach the desired force value. Experimental results are presented and discussed.
\end{abstract}

Keywords: hybrid control, on/off distributor, valve, electro-pneumatic, experimental results, force control

\section{Introduction}

At the present time in the pneumatic field, when a system requires a wide range of force control, servodistributors are currently used, e.g. Ben-Dov (1995), Edge (1987), Richer (2000), Yamada, (2003), Yin (1998). On/off distributors are used when the system is simpler and only a small range of force values are required, e.g. Ham (2005). The work presented here consists of using on/off distributors in a system that requires a wide range of force values. This has been carried out in order to reduce the cost of complex systems, e.g. Legrand (2005), Van Varseveld (1997), because present day distributors are five to ten times cheaper than servodistributors.

Using on/off distributors for reaching a desired force produces to a system with energy modulators (on/off distributors) and a continuous sub-process (cylinder). Such systems define a type of Hybrid Dynamic Process (HDP). Hybrid control, e.g. Retif (2004), Morel (2004), which is an efficient approach for controlling this kind of system. It is based on a state space model for both the energy modulator and the continuous sub-process. For this model, a control vector, depending on the number of possible configurations for the energy modulator, is defined. A formal approach has been developed for choosing a control vector to track the reference state of interest in the state space. This control has been developed for the control of $\mathrm{AC}$ machines driven by inverters. Very good dynamic performance has been obtained (Retif 2004). In this paper, the hybrid control is applied for the force control of the pneumatic cylinder where the chosen state variables of interest are the pressure in each chamber noted $p_{P}$ and $p_{N}$. In fact, the control of both pressures leads to the control of the pneumatic force. Usually in the electrical field, from where the hybrid control algorithm is issued, the time commutation of the transistors can be neglected, e.g. Retif (2004), Morel (2004), with regards to the sample time (respectively equal to few microseconds and few hundred microseconds). The main difficulty in our context is that the on/off distributors used are quite slow. In the electropneumatic field, e.g. Burrows (1972), the bandwidth of cheap on/off components is very small (between 5 and 20 Hertz) and cannot be neglected when the control frequency is of the same order. Some propositions were proposed in literature to increasing the dynamic performance of pneumatic servo-systems with digital valves. In this paper the aim is not to use PWM concept, e.g. Parnichkun (2001), for limited energy consumption, and not to increase the number of valves as in Belforte (2004), for limited cost. This problem is not present when the power modulator is a servodistributor and therefore other control algorithms are used, e.g. Noristugu (1988), Edge (1987), Brun (2002), Bouri (1996), Brun (2003), Liu (1993), because hybrid control is not appropriate with this type of component.

The study begins with the modelling of the continuous sub-process, then of the distributors, these are divided into two parts: static and dynamic models. The hybrid control algorithm is then developed. Finally, the first experimental results are presented and discussed and perspectives are announced for improving the performance of the system. 


\section{Electro-pneumatic System Modelling}

In order to determine the best distributor state for reaching the desired output value, the hybrid control requires both cylinder and distributor control models. This model must use physical parameters which can be given by industrial manufacturers or which can be obtained easily from simple experimental tests. In fact the following approach must be easy to generalise to any other electropneumatic on/off distributor.

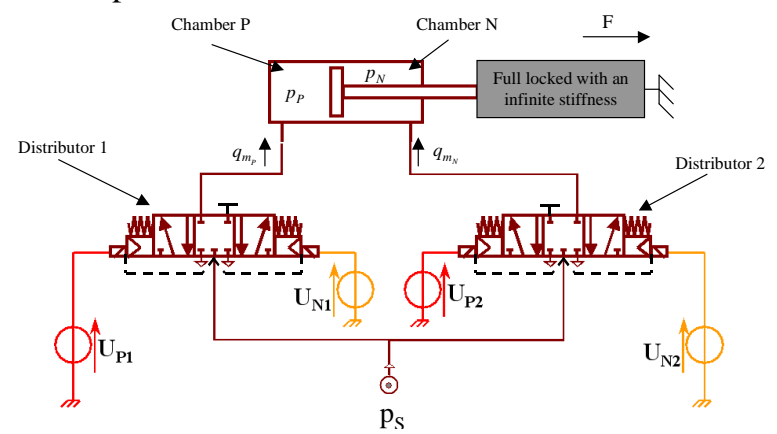

The pneumatic system consists of a pneumatic cylinder and two electropneumatic on/off distributors. The notation ' $\mathrm{P}$ ', respectively ' $\mathrm{N}$ ' on the schema in Fig. 1 is attached to elements whose positive actuation induces an increase in the exerted force, or respectively, a decrease.

Table 1 shows the nine different combinations of control vectors ( $\mathrm{C} 1$ to $\mathrm{C} 9$ ) which can be applied to the distributors. The ' 0 ' value corresponds to a null voltage and the ' 1 ' value corresponds to 5 volts. All the states where $\mathrm{U}_{\mathrm{Px}}=\mathrm{U}_{\mathrm{Nx}}=1$, are prohibited to avoid short-circuits in the electrical distributors. :

Fig. 1: Schema of the electro-pneumatic system

\begin{tabular}{|l|c|c|c|c|c|c|c|c|c|}
\hline & C1 & C2 & C3 & C4 & C5 & C6 & C7 & C8 & C9 \\
\hline $\mathrm{U}_{\mathrm{P} 1}$ & 0 & 1 & 0 & 0 & 0 & 1 & 0 & 0 & 1 \\
\hline $\mathrm{U}_{\mathrm{N} 1}$ & 0 & 0 & 1 & 0 & 0 & 0 & 1 & 1 & 0 \\
\hline $\mathrm{U}_{\mathrm{P} 2}$ & 0 & 0 & 0 & 1 & 0 & 1 & 0 & 1 & 0 \\
\hline $\mathrm{U}_{\mathrm{N} 2}$ & 0 & 0 & 0 & 0 & 1 & 0 & 1 & 0 & 1 \\
\hline
\end{tabular}

Table 1: Applicable controls

\subsection{Actuator}

The system is composed of a single rod double acting linear pneumatic cylinder (32/20). The rod of the actuator is attached to a stop end. Considering that the stiffness is infinite, there are no variations in the volume of the cylinder chambers. In our case the piston position is set to obtain the same volume in both chambers of the actuator, noted $V$ and equal about to 0,1 litre. The aim is to control the force exerted against the stop end. Considering that the dry friction forces can be neglected, the general principal of mechanics gives the expression of the force as a function of both pressures:

$$
F=S_{P} p_{P}-S_{N} p_{N}-\left(S_{P}-S_{N}\right) p_{E}
$$

So the force $\mathrm{F}$ can be controlled due to the control of the pressure in each chamber $p_{P}$ and $p_{N}$.

With the following classical assumptions, e.g. Shearer (1956), Andersen (1967), the model used for synthesise control law can be described by the system (2).

- air is a perfect gas and its kinetic energy is negligible in the chamber,

- pressure and the temperature are homogeneous in each chamber,
- the evolution in each cylinder chamber is supposed to be polytropic of index $n$,

- the temperature variation in each chamber is considered negligible with respect to the supply temperature,

- the mass flow rate leakages are neglected,

- $\quad$ supply and exhaust pressures are assumed to be constant.

$$
\left\{\begin{array}{l}
\frac{d p_{P}(t)}{d t}=\frac{n r T}{V} q_{m_{P}}\left(x_{P}\left(U_{P 1}, U_{N 1}, t\right), p_{P}(t)\right) \\
\frac{d p_{N}(t)}{d t}=\frac{n r T}{V} q_{m_{N}}\left(x_{N}\left(U_{P 2}, U_{N 2}, t\right), p_{N}(t)\right)
\end{array}\right.
$$

The main difficulty concerns the distributor mass flow rate modelling, $q_{m}$, described in the next part.

\subsection{On/off distributor}

The distributor used in this work is a 5 way / 3 position, centre position closed (from the Asco Joucomatic company) (Fig. 2a). Both components are supposed to be identical. There are two relays to move the spool to the left or to the right. These different positions allow the pressure to increase, decrease or stabilise in the chamber. According to classical hypothesis the establishment of flow is instantaneous, which means that the transient flows can be neglected, the modelling study of the 
distributor can be split into two parts : a static part giving the mass flow rate as a function of the distributor spool position $x$ and of the output port pressure $p \quad\left(q_{m}(x, p)\right)$ and a dynamic part characterising the spool dynamic $\left(x\left(U_{P}, U_{N}, t\right)\right)$. Figure $2 \mathrm{~b}$ shows the system representation of the distributor model.

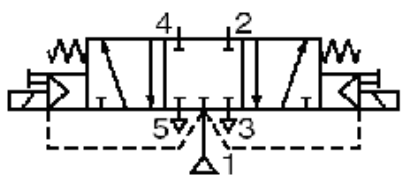

a/ Normalised representation of the distributor used

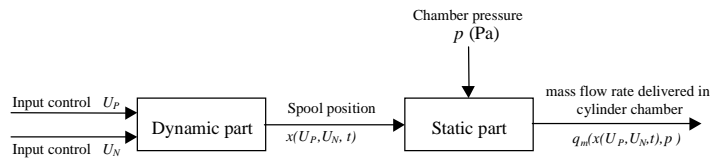

b/ Block diagram of the distributor model

Fig. 2: Distributor

\section{Dynamic part}

The main drawback of on/off distributors compared to servodistributors is their high opening and closing time. In addition, for the components tested, the time is different for opening and closing, the closing time being about double the opening time. This difference is due to the force used to carry out the operation. The opening is carried out with the electro-magnetic force and the source pressure, while the closing is done by the mechanical force of the return spring. So, the component is asymmetrical.

This property has been compensated experimentally by applying a voltage, for a small time, on the opposite relay of the distributor in order to accelerate the spool to change position (go back to the centre or to the opposite side). The time of applying the voltage was specified for each distributor and tuned experimentally.

When connecting the distributor to a pneumatic chamber, it has been seen that the low dynamic is mainly due to the delay of $15 \mathrm{~ms}$ originating from high dry friction forces. Moving the spool then takes a few milliseconds. So, for a first control model, the displacement of the spool is supposed to be instantaneous and the dynamic part of the distributor model is just modelling as a delay (Fig. 3 ). The sampling period noted $T_{s t}$, is then chosen as 20 milliseconds to guarantee that at each sampling time, the spool is either in an extreme position or in the central position. So the normalised position $x$ of the spool, has only 3 different values : $\{-1,0,1\}$.

The consequence of the delay is that the variation of the pressure in a chamber for a control at time $k T_{s t}$ depends on the previous position of the distributor spool produced by the previous control at time $(k-1) T_{s t}$. It means that the effective application of the control is delayed (Fig. 3). This problem has to be taken into account in the control algorithm.
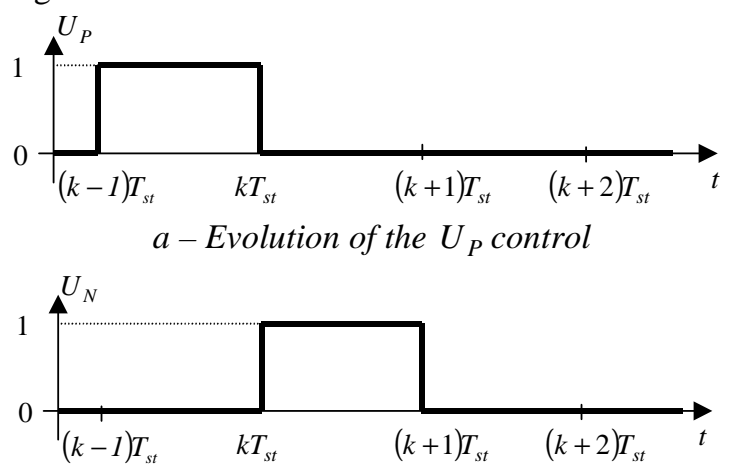

$b-$ Evolution of the $U_{N}$ control

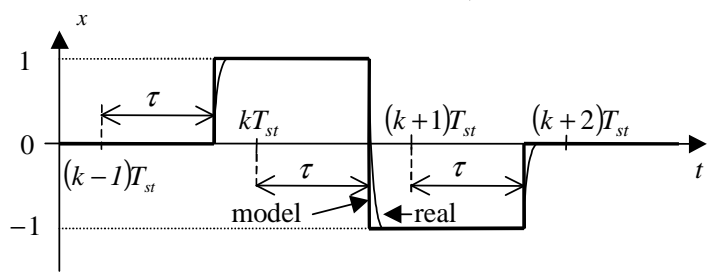

$c-$ Evolution of the normalised spool position $x$

Fig. 3: Example of the evolution of the normalised spool position of the distributor

According to the modelling hypothesis, the following dynamic model is then proposed with $\tau$ being the time delay of the spool to change position when the control is applied :

$x\left(U_{p}\left(k T_{s t}\right), U_{N}\left(k T_{s t}\right), t\right)=\left\{\begin{array}{ccc}U_{p}\left((k-1) T_{s t}\right)-U_{N}\left((k-1) T_{s t}\right) & \text { if } & k T_{s t} \leq t<k T_{s t}+\tau \\ U_{p}\left(k T_{s t}\right)-U_{N}\left(k T_{s t}\right) & \text { if } & k T_{s t}+\tau \leq t<(k+1) T_{s t}\end{array}\right.$

With three possible states (Table 1):

$\left\{\begin{array}{l}U_{P}=0 \\ U_{N}=0\end{array}\right.$ or $\quad\left\{\begin{array}{l}U_{P}=1 \\ U_{N}=0\end{array}\right.$ or $\left\{\begin{array}{l}U_{P}=0 \\ U_{N}=1\end{array}\right.$

\section{Static part}

The static part of the on/off distributor model should consist of the expression of the mass flow rate through each useful restriction as a function of the chamber pressure $p$ and of the normalised spool position $x$. As for the determination of the dynamic model, it has been considered that the movement of the spool is instantaneous, it is just necessary to know the mass flow rate characteristics of the on/off distributor for the full opening of the useful restrictions. According to Fig. 1 and 2, these restrictions are :

- restrictions 1 to $4\left(x_{P}=1\right)$ and 4 to 5 $\left(x_{P}=-1\right)$ for distributor 1 ,

- restrictions 1 to $2\left(x_{N}=-1\right)$ and 2 to 3

$\left(x_{N}=1\right)$ for distributor 2 .

According to the ISO 6358 (1989) standard, a test bench was realised (see Fig. 4a) to measure the 
mass flow rate characteristics to determine the flow parameters $\mathrm{b}$ and $\mathrm{C}$ used by the standard approximation (4). This model gives the mass flow rate evolution as a function of the upstream pressure and temperature and of the downstream pressure defined along the flow in the restriction.

Figure $4 \mathrm{~b}$ shows an example of the experimental characteristics obtained compared to those obtained from the identified $\mathrm{b}$ and $\mathrm{C}$ parameters according to the ISO 6358 standard (1989).

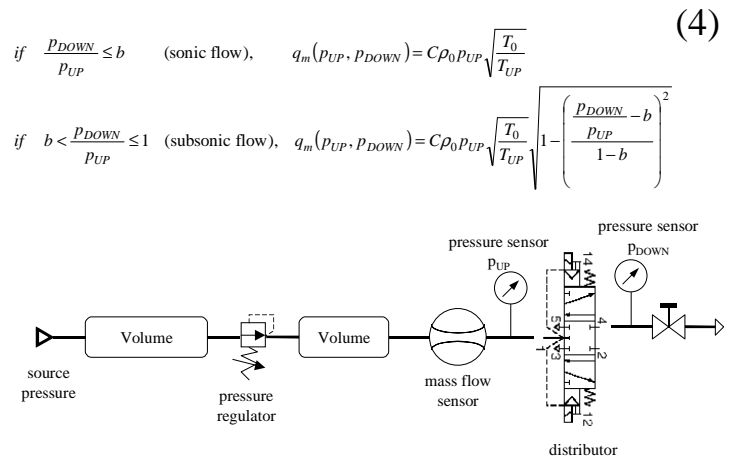

a/ Test bench for on/off distributor characterisation

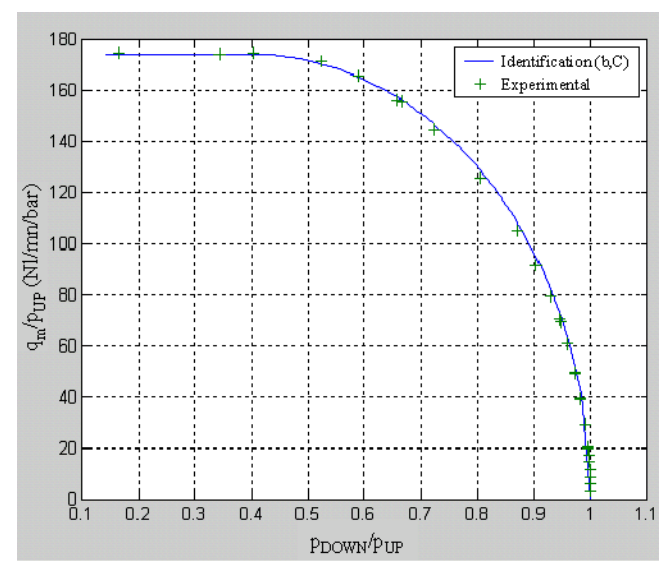

b/ Experimental and identified mass flow rate distributor characteristics

Fig. 4: Distributor characterisation

As the four characteristics are very similar, the same couple of parameters $(b, C)$ according to the ISO 6358 standard has been determined for modelling every restriction :

- $\quad$ Critical pressure ratio $b=0.4$,

- Sonic conductance $C=174 \mathrm{Nl} / \mathrm{mn} / \mathrm{bar}$

So the mass flow rates entering the 2 chambers can be expressed as a function of the spool position and of the chamber pressure by :

$$
\begin{aligned}
& q_{m_{P}}\left(x_{P}, p_{P}\right)=\left\{\begin{array}{ccc}
q_{m}\left(p_{S}, p_{P}\right) & \text { for } & \mathrm{x}_{\mathrm{P}}=1 \\
0 & \text { for } & \mathrm{x}_{\mathrm{P}}=0 \\
-q_{m}\left(p_{P}, p_{E}\right) & \text { for } & \mathrm{x}_{\mathrm{P}}=-1
\end{array}\right. \\
& q_{m_{N}}\left(x_{N}, p_{N}\right)=\left\{\begin{array}{ccc}
-q_{m}\left(p_{N}, p_{E}\right) & \text { for } & \mathrm{x}_{\mathrm{N}}=1 \\
0 & \text { for } & \mathrm{x}_{\mathrm{N}}=0 \\
q_{m}\left(p_{S}, p_{N}\right) & \text { for } & \mathrm{x}_{\mathrm{N}}=-1
\end{array}\right.
\end{aligned}
$$

The $q_{m}$ function in (5) and (6) is given by (4) in which the flow parameters $\mathrm{b}$ and $\mathrm{C}$ have the previous determined values and the upstream temperature is considered equal to the source temperature whatever the flow direction (according to hypotheses taken for the cylinder model section 2.1).

The equations (3) to (6) enable knowledge of each variable appearing in the system to be obtained (2) which together define the global control model of the system presented in Fig. 1.

\section{Hybrid Control}

\subsection{Hybrid Control Principle}

Hybrid control uses a hybrid model where the continuous state variables of the continuous subprocess depend on the energy modulator's configuration:

$$
\underline{\dot{X}}(\mathrm{t})=\mathrm{f}(\underline{\mathrm{X}}(\mathrm{t}), \underline{\mathrm{U}}(\mathrm{t}))
$$

$\underline{\mathrm{X}} \in \mathfrak{R}^{\mathrm{n}}$ and $\underline{\mathrm{U}}(\mathrm{t})$ is a $\mathrm{m}$-dimensional vector that is finite

$$
\mathrm{U} \in\left\{\mathrm{U}_{1}, \mathrm{U}_{2}, \ldots, \mathrm{U}_{\mathrm{N}}\right\}, \mathrm{N} \geq 2
$$

For a short sampling period $\mathrm{T}_{\mathrm{st}}$, the model can be written as(Euler method):

$$
\underline{\mathrm{X}}(\mathrm{k}+1)=\underline{\mathrm{X}}(\mathrm{k})+\mathrm{f}(\underline{\mathrm{X}}(\mathrm{t}), \underline{\mathrm{U}}(\mathrm{t})) \cdot \mathrm{T}_{\mathrm{st}}
$$

Assuming that full state is available for measurement, at time $\mathrm{kT}$, the state $\underline{X}(\mathrm{k})$ is known.

Via the dynamic model of the system (1), the state at time $(\mathrm{k}+1) \mathrm{T}_{\mathrm{st}}$, noted $\underline{X}_{\mathrm{j}}(\mathrm{k}+1), \mathrm{j} \in \mathrm{N}$, for each possible value of the control set can be calculated. $\mathrm{N}$ directions are defined as $\underline{\mathrm{dj}}=\underline{X}_{\mathrm{j}}(\mathrm{k}+1)-\underline{X}(\mathrm{k})$.

For a given reference state $\underline{X}^{\#}$, Hybrid Control consists of calculating the $\mathrm{N}$ possible direction of the continuous state vector evolution $d$, choosing a control configuration in order to track this reference state in the state space.

For the bi-dimensional example in Fig. 5, the desired value (target point) can be placed in the plane $X_{1}$ and $X_{2}$. To track this reference, at each sample time, hybrid control proceeds as follows:

- $\quad$ it acquires the state of the system at time $\mathrm{kT}_{\mathrm{st}}$ $\left(X_{1}\left(k T_{s t}\right)\right.$ and $X_{2}\left(k T_{s t}\right)$ see Fig. 5)

- knowing the state of the system in the state space at time $k T_{s t}$, this algorithm solves the system model equations, and calculates the different directions $\mathrm{dj}, 1 \leq \mathrm{j} \leq \mathrm{N}$ of the continuous state vector evolution corresponding to the application of $\mathrm{j}^{\text {th }}$ configuration of the energy modulator ( $\underline{\mathrm{d} 1}$ to d5 in Fig. 5)

- knowing the target point, this algorithm selects the optimal configuration. For this many techniques are possible. For example, the configuration chosen can be the one that 
minimises the Euclidean distance between the different reachable points and the target point.

- this algorithm chooses the shortest euclidean distance ( $\underline{\mathrm{d} 4}$ in Fig. 5) and the corresponding control $\left(\mathrm{U}_{4}\right)$ is applied to the energy modulators for all the sampling period.

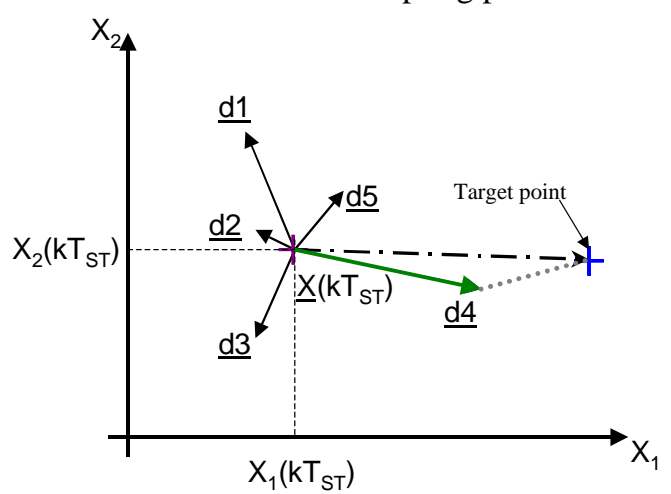

Fig. 5: Principle of hybrid control

\subsection{Application to the pneumatic system}

For the system represented by Fig. 1, the pressures in both chambers $\mathrm{P}$ and $\mathrm{N}$ constitute the state space $\underline{X}(t)=\left[p_{p}, p_{n}\right]^{t}$. The state space is of dimension 2 , so it can be represented by a $\left(p_{N}, p_{P}\right)$ plane. Two distributors enable three different states (pressure admission, closed and pressure exhaust) to be established leading to nine different control vectors $\mathrm{C} 1$ to $\mathrm{C} 9$ (see table 1$)$.

The objective is, knowing the pressure at the sampling instant $k T_{s t}$, to estimate the evolution of the pressures at the next sampling instant, $(k+1) T_{s t}$, in both chambers $\mathrm{P}$ and $\mathrm{N}$ for the nine controls $(\mathrm{C} 1$ to C9) and then to choose the best control for reaching the desired force.

At each sample time, the pressure in each chamber is measured. The hybrid control algorithm calculates the nine directions $\underline{\mathrm{d} 1}$ to $\underline{\mathrm{d} 9}$ reachable at the next sample time in the state space by integrating the pressure differential system (2) using equations (3) to (6). See the block diagram in Fig. 6.

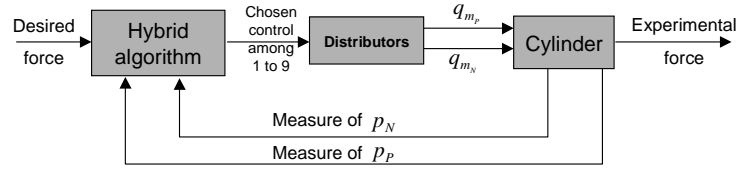

Fig. 6: System structure

The target is fixed according to equation (1). For a given desired pneumatic force $F$, the target is defined by a one-dimensional equation:

$$
p_{P}=\left(\frac{S_{N}}{S_{P}}\right) p_{N}+\left(\frac{F}{S_{P}}+\frac{S_{P}-S_{N}}{S_{P}} p_{E}\right)
$$

So the target is a point of the straight line defined by equation (7) in the $\left(p_{N}, p_{P}\right)$ plane. The algorithm calculates the nine possible directions ( $\underline{\mathrm{d} 1}$ to d9 in Fig. 7). Then it chooses the control configuration that corresponds to the lowest Euclidean distance in the physical domain (d6 for the desired force F1 and $\mathrm{d} 4$ for the desired force F2 in Fig. 7 because d6 leads out of the physical domain in this case).

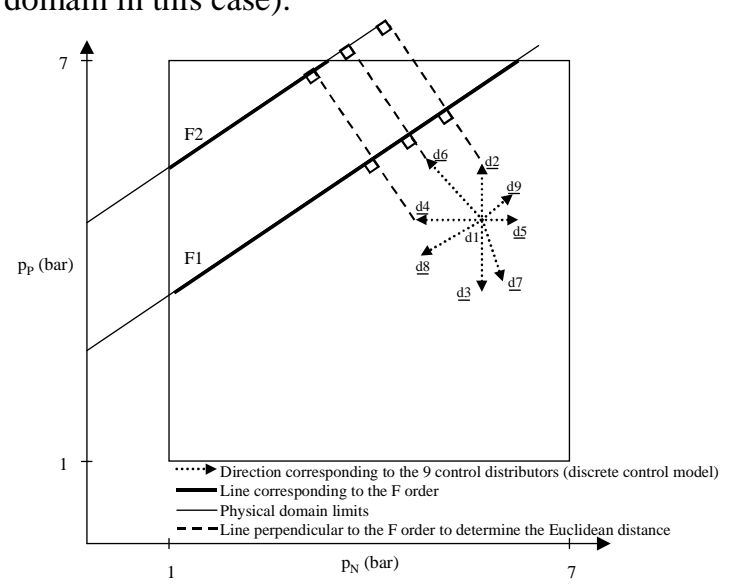

Fig. 7 : Example of control choice

\section{Experimental Result}

The following results give an illustration of the overall control performance. The test bench is presented in Fig. 1. All the tests were realised with a DSP card from dSpace : DS1104. Programs implemented in DS1104 were Matlab/Simulink with $\mathrm{C}$ code. Value 1 given by table 1 means that the relay of the distributor is supplied at $5 \mathrm{~V}$ and consumes $1.1 \mathrm{~W}$. Value 0 means $0 \mathrm{~V}$. The exhaust pressure value (1bar) and the supply pressure (7bar) limit the pressure.

\subsection{Repetitive sequence of step responses}

This part will compare two different results :

- In the first plots (Fig. 8), the desired force is $0 \mathrm{~N}$ for 2.5 seconds and $230 \mathrm{~N}$ for 2.5 seconds.

- In the second plots (Fig. 9), the sequence of force is $0 \mathrm{~N}$ for 3 seconds, $50 \mathrm{~N}$ for 0.5 seconds and $230 \mathrm{~N}$ for 2 seconds.

All the transitions are obtained step by step.

At the beginning of the process, the pressures in the chambers $\mathrm{P}$ and $\mathrm{N}$ are 1 bar (the inferior left corner of the physical limit). At this stage, the force $50 \mathrm{~N}$ is accessible with $\mathrm{C} 9$ control for $T_{s t}$ and then $\mathrm{C} 1$ to close the distributor and maintain the pressure in the chambers. At $50 \mathrm{~N}, 230 \mathrm{~N}$ is an accessible force with the C9 control. Then in order to obtain $0 \mathrm{~N}$, the chosen algorithm exhausts the chambers $\mathrm{P}$ and $\mathrm{N}$ with control $\mathrm{C} 8$ and maintains this value.

So the aim of the next two results is to show the difference in accessing $230 \mathrm{~N}$ directly or passing by a step at $50 \mathrm{~N}$.

In the first case, at the beginning of the test, the experimental force was equal to $0 \mathrm{~N}$ (see point (0) in Fig. 8a), the pressures in the $\mathrm{P}$ and $\mathrm{N}$ chambers are 1 bar (see point (0) in Fig. 8b), the control vector is C8 ((see time around 5 seconds in Fig. 8c) which 
corresponds to emptying each chamber. When the desired force equals $230 \mathrm{~N}$, the control algorithm increases the pressure in chamber $\mathrm{P}$ (see point (1) in Fig. 8b). A big overshoot (about $85 \mathrm{~N}$ ) of desired force can be seen in Fig. 8a (see point (1)). A new control vector is selected by the hybrid control algorithm to decrease the force value (see point (2) in Fig. 8a) and converges to the line corresponding to the desired force in the $\left(p_{P}, p_{N}\right)$ plane (see point (2) in Fig. 8b). Between points (2) and (3) the control vector is $\mathrm{C} 1$ : this value theoretically close the distributor and maintains the pressure in each chamber. It is important to note that experimentally the two pressures and therefore the force continue to evolve. This phenomenon can be due to the thermal exchanges taking place between the cylinder chambers and the environment. So the static stage is reached after about 1.5 seconds and the steady state error is about $10 \mathrm{~N}$ (see point (3) in Fig. 8a). At this stage all the control vectors will generate a greater steady state error than $10 \mathrm{~N}$ and so the control vector is kept at $\mathrm{C} 1$ until the desired force evolves.

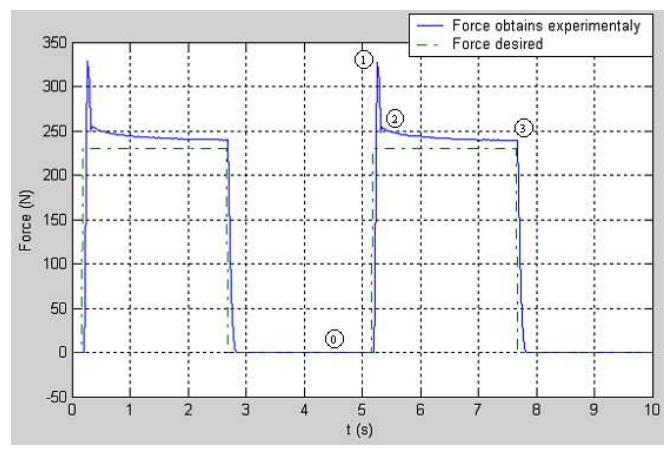

a/ Time evolution of the desired and experimental forces

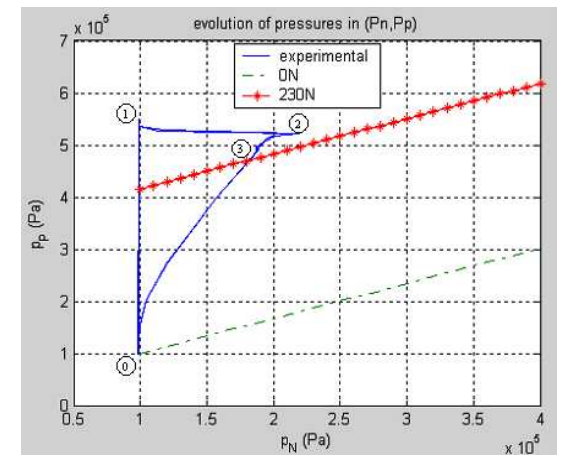

$b /$ Pressure evolution in the state plane $\left(p_{N}, p_{P}\right)$

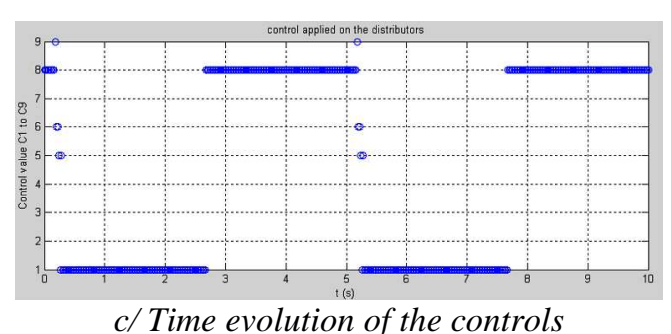

Fig. 8: Desired force in one step
The next test reaches $230 \mathrm{~N}$ too, but first passing by a stage at $50 \mathrm{~N}$. At the beginning of the process, the experimental force equals $0 \mathrm{~N}$ as it did previously (see point (0) in Fig. 13). So the desired force equals $50 \mathrm{~N}$ (see point (1) in Fig. 9a) by applying controls $\mathrm{C} 9$ and $\mathrm{C} 4$ (see Fig. 9c), $\mathrm{C} 1$ to close the distributor and maintain the pressures. When the desired force reaches $230 \mathrm{~N}$ (see point (2) in Fig. 9a), the algorithm applies control C2 and C9 (see 4 second time value in Fig. 9c). Point (2) to point (3) is due to thermal exchange (see the evolution of the chambers in Fig. 9b). The steady state error is about $10 \mathrm{~N}$ as seen previously. Finally the return to $0 \mathrm{~N}$ is carried out by the $\mathrm{C} 3$ and $\mathrm{C} 8$ controls. Each application of a control can be observed by a break in the $\left(p_{P}, p_{N}\right)$ plane.

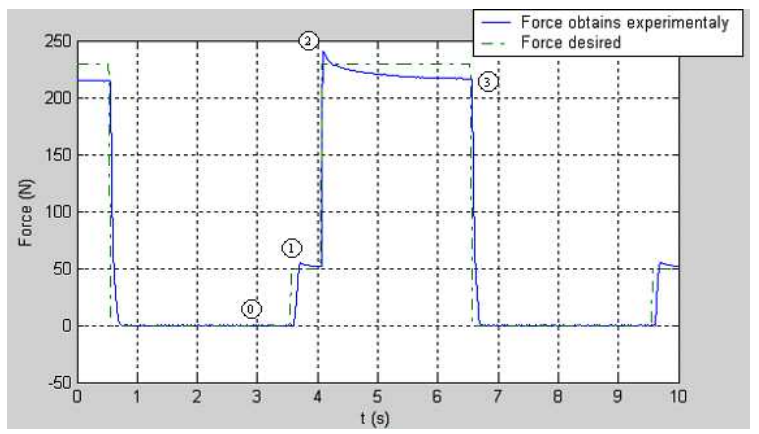

a/ Time evolution of the force

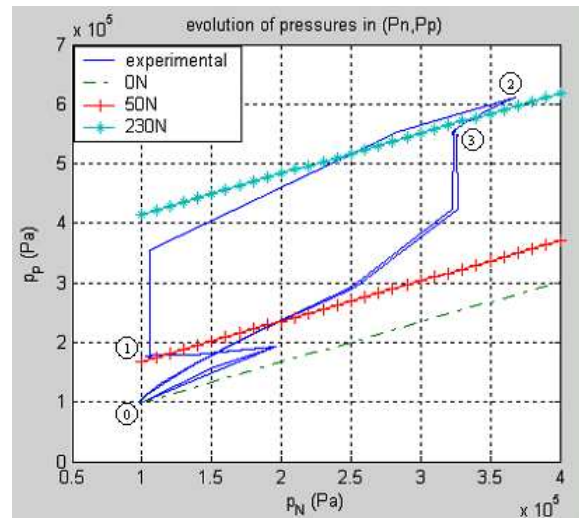

$b /$ Evolution of the pressure in the plane $\left(p_{N}, p_{P}\right)$

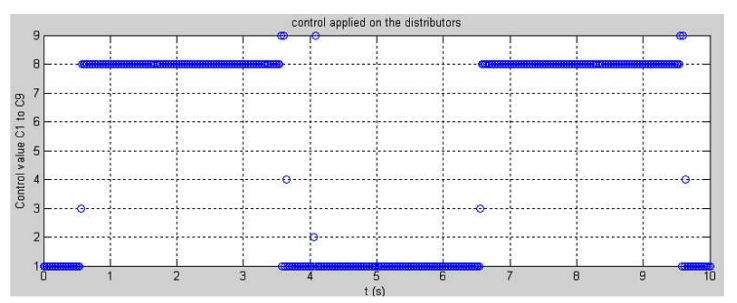

c/ Time evolution of the controls

Fig. 9: Desired force in two steps

The main difference between the previous two tests is the difference in the size of the overshoot which is reduced from $85 \mathrm{~N}$ (Fig. 8a) to about $10 \mathrm{~N}$ (Fig. 9a) by using an intermediary stage for the desired force. It can be noted in Fig. 9a that the second case, using an intermediary step in the desired force, obviously requires more time to 
obtain the final objective of $230 \mathrm{~N}$ and is more spread out on the $\left(p_{P}, p_{N}\right)$ plane (Fig. $8 \mathrm{~b}$ and $9 \mathrm{~b}$ ).

\subsection{Random sequences of step responses}

Figure 10a shows the experimental results for different tested forces. Figure $10 \mathrm{~b}$ presents the corresponding control vector values.

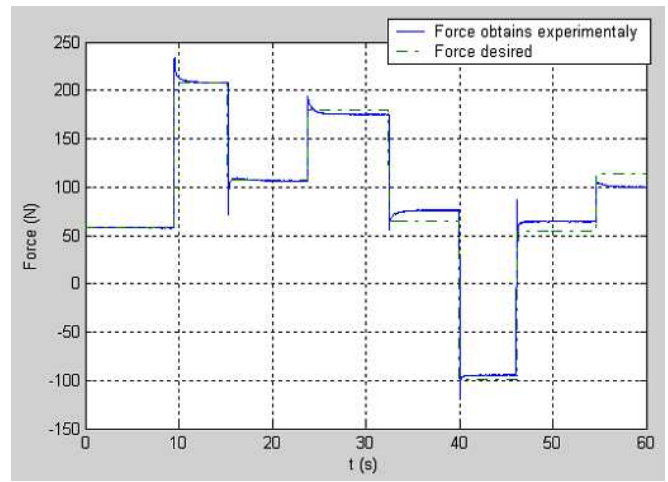

a/ Force time evolution

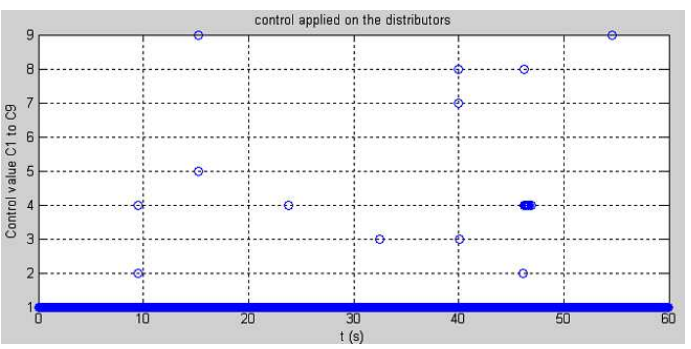

b/ Control time evolution

Fig. 10: Random sequences of step response

It can to seen that the desired forces are quickly obtained and that the root mean square steady state error is small (equal to about $3 \mathrm{~N}$ ). The mean absolute error is about $6 \mathrm{~N}$. When a force is obtained, the system applies the $\mathrm{C} 1$ control to maintain the pressure in the chambers and there is no consumption of power. This new control strategy seems to be very interesting in term of energy consumption (Brun 1999).

\section{Conclusion}

The contribution of this paper concerns:

- Firstly, the model synthesis and parameterisation of an on/off electropneumatic valve,

- secondly, the application of the hybrid method developed for electrical engine control, e.g. Retif (2004), of a system composed of a pneumatic cylinder and two on/off distributors designed for force control.

Experimental results show that the principle of controlling the force by quantified components is realisable. Of course it needs to be perfected for static performances, but the results are satisfactory. On/off control is a promising alternative for force control because of the low cost (compared to servodistributors) and the good performance obtained. Moreover there are no control parameters to tune.

It is possible to improve the system in three different ways :

1. improvement of the control algorithm.

2. add a closed loop by placing a force sensor at the end of the piston (to measure the force obtained) and to use a classical supplementary control loop (Doyle, 1992) as PID.

3. to replace the distributors by ones which have a smaller sonic conductance $\mathrm{C}$.

The first way is the cheapest of the three. The algorithm can be improved to determine several force step values accessible by only one control, in order to reach the desired force. This technique will enable the desired forces to be reached with only a small overshoot (see Fig. 9a compared to Fig. 8a). In addition, the smaller the step, the smaller the thermal exchange, but the longer the time needed to access the final desired force.

The second way requires adding a force sensor. At the moment the system has two sensors to measure the pressure in each chamber, and the force is reconstructed using equation (1). At this stage dry friction is not taken into account. With a force sensor, it would be possible to determine the real force and so decrease the steady state error.

The third way is a distributor-sizing problem. Accessible forces at time $k T_{s t}$ are quantified. So the smaller the sonic conductance is, the smaller the difference in the accessible force and the actual force, but the delay in reaching the desired force is greater. A compromise between dynamic and static performance must be carried out.

Another possible improvement is to apply a higher voltage to the distributor relay for a small time to accelerate the displacement of the spool (Van Ham and al, 2005, Lin 2005). This method would enable the time of applying a control (at the moment $20 \mathrm{~ms}$ ) to be reduced and so decrease the pressure evolution in the chamber per control. This also would decrease the value of the accessible force in one control, and so decrease the transitional time due to the thermal exchange. Also it would reduce the time to reach the desired force.

Future work will focus on improving the algorithm and applying a higher voltage to the distributor relay to reduce the spool delay.

\section{Notation}

b critical pressure ratio

C sonic conductance $(\mathrm{Nl} / \mathrm{mn} / \mathrm{bar})$

$\mathrm{F}$ force $(\mathrm{N})$

$\mathrm{S} \quad$ piston cylinder area $\left(\mathrm{m}^{2}\right)$

$\mathrm{T}$ temperature $(\mathrm{K})$

$\mathrm{T}_{\mathrm{st}} \quad$ sampling period ( $\mathrm{s}$ )

$\mathrm{U} \quad$ boolean distributor input (null) 
V pneumatic cylinder chamber volume $\left(\mathrm{m}^{3}\right)$

$\mathrm{k} \quad$ sampling period index

$\mathrm{n} \quad$ polytropic constant

$\mathrm{p} \quad$ pressure $(\mathrm{Pa})$

$\mathrm{q}_{\mathrm{m}} \quad$ mass flow rate $(\mathrm{kg} / \mathrm{s})$

$\mathrm{r} \quad$ perfect gas constant $(\mathrm{J} / \mathrm{kg} / \mathrm{K})$

$\mathrm{t}$ time $(\mathrm{s})$

$\mathrm{x}$ normalised position of the distributor spool (null)

$\tau \quad$ spool time delay to move after the control has been applied (s)

$\rho \quad$ specific mass $\left(\mathrm{kg} / \mathrm{m}^{3}\right)$

\section{Subscript and Superscript}

\section{UP upstream}

DOWN downstream

$\mathrm{P}$ relative to an increase of force

$\mathrm{N}$ relative to a decrease of force

E exhaust

s supply

0 reference

1 distributor connected to chamber $\mathrm{P}$

2 distributor connected to chamber $\mathrm{N}$

\section{References}

Andersen, B.W. 1967. The analysis and design of pneumatic systems. New-York : John Wiley and Sons, 302p.

Belforte, G., Mauro, S., Mattiazzo, G. 2004. A method for increasing the dynamic performance of pneumatic servosystems with digital valves, Mechatronics, Vol 14 Issue 10, p 1105-1120

Ben-Dov, D., Salcudean, S.E. 1995. A force controlled pneumatic actuator, IEEE Transactions on Robotics and Automation, Vol 11, Issue 6, p 906-911.

Bouri, M., Thomasset, D., Scavarda, S. 1996. Integral sliding mode controller of a rotational servodrive. Third Japan Hydraulics and Pneumatics Society, Tokyo, p 145150.

Brun, X., Thomasset, D., Sesmat, S., Scavarda, S. 1999. Limited energy consumption in positioning control of electropneumatic actuator, Power Transmission \& Motion Control, Bath, UK, p 199-211.

Brun, X., Thomasset, D., Bideaux, E. 2002. Influence of the process design on the control strategy: application in electropneumatic field, Control Engineering Practice, Volume 10, Issue 7, p 727-735.

Brun, X., Thomasset, D., Scavarda, S. 2003. Hybrid control for switching between position and force tracking, The Fourth International Symposium on Fluid Power Transmission and Control, Wuhan, China.

Burrows, C.R. 1972. Fluid Power Servomechanisms. London : Van Nostrand Reinhold Company, 237 p.

Doyle, J.C, Francis, B.A, Tannenbaum, A.R 1992. Feedback control theory, Ed. Maxwell Macmillan International, $227 \mathrm{p}$.

Edge, K.A, Figeredo, K.R.A. 1987. An adaptively controlled electrohydraulic servo-mechanism: Part 1: Adaptive controller design - Part 2: Implementation. In: Proc. Instn. Mech. Engrs. Part B, Vol 201, N³, p 175180 and p. 181-189.
Ham, R.V, Verrelst, B., Daerden, F., Vanderborght, B., Lefeber, D. 2005. Fast and accurate pressure control using on/off valves, International Journal of Fluid Power, Vol 6, $\mathrm{N}^{\circ} 1$.

International Standard ISO Norm $\mathbf{6 3 5 8} 1989$. Pneumatic Fluid Power- Components Using Compressible Fluids, Determination of Flow-rate Characteristics.

Legrand X., Retif J.-M., Smaoui M., Brun X., Thomasset D., Lin-Shi X. 2005. Hybrid control with on/off electropneumatic standard valve for tracking positioning, Bath Worksh. on Power Transmission \& Motion Control, England.

Lin, C., Chen, C., Liu, V. 2005. A new time delay compensating scheme for electro-hydraulic system, International Journal of Fluid Power, Vol 6, $\mathrm{N}^{\circ} 1$,

Liu, P., Dransfield, P. 1993. Intelligent control of air servodrives using neural networks. Proc. of Second Japan Hydraulics and Pneumatics Society, Tokyo, p. 381-399.

Morel, F., Retif, J.M., Lin-Shi, X.F., Llor, A. 2004. Fixed switching frequency hybrid control for a permanent synchronous machine, IEEE International Conference on Industrial Technology (ICIT'04), Tunisia.

Noritsugu, T., Wada, T., Yanosaka, M. 1988. Adaptive control of electropneumatic servo system. In: 2nd Int. Symp. On Fluid -Control, Measurement, Mechanics and flow visualisation. Sheffield, England, p. 285-289.

Parnichkun, M., Ngaecharoenkul, C. 2001, Kinematics control of a pneumatic system by hybrid fuzzy PID, Mechatronics, Vol 11, Issue 8, p1001-1023

Richer, E., Hurmuzulu, Y. 2000. A high performance pneumatic force actuator system : Part I - Nonlinear Mathematical Design, Part II - Nonlinear Controller Design, Journal of Dynamic Systems Measurement and Control, Volume 122, Issue 3, p 416-425 and p 426-434.

Retif, J.M., Lin-Shi, X.F., Llor, A., Arnalte, S. 2004. New control for a synchronous machine, the hybrid control, EPE-11th International Power Electronics and Motion Control Conference.

Retif, J.M., Lin-Shi, X.F., Llor, A. 2004. A new hybrid direct-torque control for a winding rotor synchronous machine, PESC'2004: 35th IEEE Power Electronics Specialists Conference.

Shearer, J.L. 1956. Study of pneumatic processes in the continuous control of motion with compressed air. Parts I and II. Trans. Am. Soc. Mech. Eng., Vol. 78, p.233-249.

Van Varseveld, R.B., Bone, G.M. 1997. Accurate position control of a pneumatic actuator using on/off solenoid valves, Transactions on Mechatronics, IEEE/ASME, Volume 2, Issue 3, p 195-204.

Yamada, H., Kudomi, S., Muto, T. 2003. Development of a pneumatic force display (application to a master slave system), International Journal of Fluid Power, Vol $4, n^{\circ} 1$.

Yin, Y.B., Araki, K. 1998. Modelling and analysis of an asymmetric valve controlled single-acting cylinder of a pneumatic force control system, SICE'98. Proceedings of the $37^{\text {th }}$ SICE Annual Conference, Chiba, Japan, p 10991104 . 

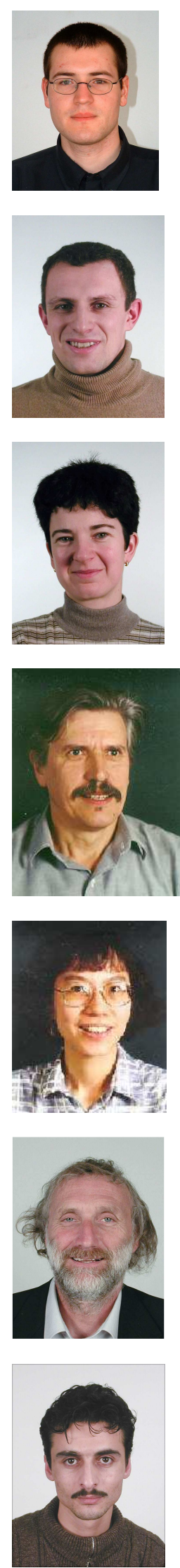

\section{Arnaud Sellier}

Was received the engineering degree in electrical engineering in 2005 from the Institut Nationale des Sciences Appliquées (INSA) of Lyon, France, and the Master Science degree in automatic from the LAI (Laboratoire d'Automatique Industriel) laboratory, INSA of Lyon. He is now a PHD student

\section{Xavier Brun}

Was born in France in 1973. He is $\mathrm{PhD}$ graduate from INSA Lyon Scientific and Technical University in 1999. Since 2001, Dr Brun is associate professor at Laboratoire d'Automatique Industrielle (LAI) in INSA, France. His current interests concerns the implementation and comparison of controls laws for Fluid Power actuators.

\section{Syslvie Sesmat}

She presented her doctoral thesis entitled "Modelling, simulation and control of an electropneumatic servovalve" in 1996 at INSA of Lyon. She is currently employed as a research associate at the Laboratoire d'Automatique Industrielle of the INSA Lyon, France.

\section{Jean-Marie Rétif}

Was born in France in 1946. Was received the PHD in 1969 in the field tuning control. Since 1979, he has been working in the field of electrotechnics at CEGELY. His researches concern advanced control of AC machines, pulse with modulations methods. His current interest concerns the hybrid control.

\section{XueFang Lin Shi}

Was received the PHD degree in applied computer science and automatic in 1992 from INSA of Lyon, France. Since 1994, she has been a lecturer at the department of Electrical Engineering of the and has joined the Centre de Génie Electrique de Lyon (CEGELY). Her research interests are control and observers for electrical driver

\section{Daniel Thomasset}

$\mathrm{He}$ is currently a professor at the Laboratoire d'Automatique Industrielle, Lyon, France, where he is the head of Fluid Power, Transport and Robotic team. His research interests include control and sizing of Fluid Power system for transport application.

\section{Mohamed Smaoui}

Was born in Sfax, Tunisia, in 1976. He received the Electrical Engineering degree, in 2000, from ENIS of Sfax, Tunisia, and the M.Sc. degree and the D.Sc. degree, both in automation, respectively in 2001 and 2004, both from INSA of Lyon, France. Since 2005, he is assistant professor at the department of Mechanical Engineering at INSA of Lyon, France. 